\title{
Identification of unmet clinical needs in the field of nephrology - A modified bio-design approach
}

\author{
Pranay Arun-Kumar ${ }^{*}$, Shreya Sridhar ${ }^{2}$, Jagdish Chaturvedi $^{3 *}$, Ravi Prakash Deshpande ${ }^{4}$ \\ ${ }^{1}$ Product Designer, National Institute of Design, Ahmadabad, India \\ ${ }^{2}$ Biomedical Engineer, InnAccel Acceleration Services, Bangalore, India \\ ${ }^{3}$ ENT Consultant, Apollo Hospitals, Bangalore; Director, Clinical Innovations, InnAccel Acceleration Services, Bangalore, India \\ ${ }^{4}$ Senior Nephrologist, St. John's Medical College Hospital, Bangalore, India
}

\begin{abstract}
In India, the incidences and risks of Chronic Kidney Disease (CKD) have been rising alarmingly due to the rising prevalence of Hypertension and Diabetes patients. The treatment for CKD is unaffordable for most of the patients suffering from this condition. The lack of access to quality care in rural and suburban India further impacts the plight of CKD patients. These inconsistencies and gaps in effective treatment are equally present in most Nephrology related disorders. To address these issues, the authors used a modified version of the biodesign innovation process, originally developed by Stanford University, to identify unmet clinical needs in the field of nephrology from the perspective of developing new innovative medical devices to fit the evolving MedTech ecosystem in India. A multidisciplinary team, involving a doctor, an engineer and a designer, identified 54 unmet needs with significant negative outcomes from a 1 month clinical immersion held at a tertiary referral hospital in Southern India. 4 rounds of pre-caliberated filters were applied on these needs to identify the ten most compelling clinically validated needs for the phase of invention. This article talks about the modified biodesign process used, the top ten unmet clinical needs identified and the team's findings during the study.
\end{abstract}

\section{Introduction}

India has an estimated population of 1.27 billion. Recent estimates peg the prevalence of stage 4-5 Chronic Kidney Disease (CKD) to be $0.8 \%$ of the population, which comes up to over 10 million Indians. With an incidence of 151-163 per million population, End Stage Renal Disease (ESRD) is definitely growing at a fast rate [1]. It is also known that hypertensive and diabetic patients are at a higher propensity to develop kidney diseases and these account for $29.8 \%$ and $4.8 \%$ of the Indian population respectively $[2,3,4]$. A significant portion of the population, therefore, is at a growing risk of developing CKD.

CKD patients, if not treated at the appropriate stage of the illness, suffer from irreversible organ damage and a life-long dependency on artificial dialysis and medical treatment. The problems faced by CKD patients are complex, chronic and multi-faceted. CKD is an outcome of poor or ineffective functioning of the kidneys. Patients with CKD stages 1-3 are generally asymptomatic. Typically, it is not until stages 4-5 that endocrine/metabolic derangements or disturbances in water or electrolyte balance become clinically manifest [5]. The lack of awareness and delay in treatment leads to a severity of complications associated with the disease. With increasing severity of the chronic condition, the treatment becomes more expensive. Specialized centres for treatment are few and concentrated in major urban areas in India, leading to an expenditure of time and money for patients coming from remote areas [6]. The medical devices and diagnostics used are expensive as almost $75 \%$ of them are imported. Most devices present in developing countries have been designed for use in developed countries, and there are very few local manufacturers capable of designing complex technologies such as the hemodialysis machines [7].

While most of the patients of kidney disease themselves have no medical insurance cover, insurance schemes do not cover life-long illnesses, and thus, almost all kidney disease patients have to pay from their pockets [8]. In India $80 \%$ of the population is not covered by any sort of insurance at all. Medical rehabilitation is also a long and arduous process, involving numerous tests and diagnostics before the appropriate treatment can be prescribed, thus leading to extensive morbidity and hospitalization costs in some cases.

The lack of affordable and accessible technology and the use of improvised solutions spurred the authors to work towards the development of innovative technology suited to fit the Indian healthcare system in the field of Nephrology. A prerequisite to developing the technology is identifying the right need. This article describes how the authors use a modified biodesign process, originally developed by Stanford University, to identify unmet clinical needs in the field of Nephrology. This article also highlights the methods and materials used for the study, the results obtained thereafter, and a brief overview of the Indian Medtech ecosystem.

\section{Materials and methods}

The process employed is a part of the traditional bio-design process which involves three phases: identify, invent and implement $[9,10]$.

Correspondence to: Pranay Arun-Kumar, Product Designer, National Institute of Design, Ahmadabad, India, E-mail: pranay.arunkumar@gmail.com

Jagdish Chaturvedi, ENT Consultant, Apollo Hospitals, Bangalore; Director, Clinical Innovations, InnAccel Acceleration Services, Bangalore, India, E-mail: jagdishc@innaccel.com

Key words: nephrology, biodesign, needs analysis, needs filtering, kidney disease

Received: March 07, 2017; Accepted: March 25, 2017; Published: March 28 2017 
In the "Identify" phase, the observers record negative or undesirable outcomes in the care process of a specific focus area, in our case, Nephrology. These negative outcomes are translated into structured need statements that highlight the desired change in the problem in a specific target population at a location where the problem is most significant. These need statements undergo a structured filtering process in order to arrive at a list of top needs in the space. In the "Invent" phase, the team brainstorms to find solutions that address the top need. This includes identification of stakeholders, a thorough Intellectual Property landscape search and development of preliminary prototypes. In the "Implement" phase, the team decides how to take forward the innovation so that it reaches the market. This involves creation of business plans and modelling, development strategies, competitive strategy, etc. This section describesthe steps carried out and the results gathered thereof from the Identify phase or phase of identification only.

The phase of identification was used to find unmet clinical needs and validate them in a clinical setting. The aim was to identify inefficiencies, and hazards, with potential, or occurring negative outcomes in patient care. A multi-disciplinary team, including a designer, an engineer, a senior Nephrologists and a Stanford Biodesign trained clinician, performed clinical observations at a hospital in the Department of Nephrology for a period of 4 weeks. These observations were made by shadowing clinicians and patients on a routine basis, observing procedures, finding out the patient history, and following up with patients as their treatment progressed. The observations were recorded in the form of dockets, each of which carried patient details, such as age, gender, the patient history, observation, patient pathway, patient follow-up, and the time, date and place where the observation is made. From each observation the negative outcome was highlighted and converted into a clinical need for a solution.

The needs were then filtered and prioritized using some quantifiable metrics to obtain a more robust collection of high impact and context specific needs. The filtration process was conducted in four levels. The first round of filtration consisted of eliminating redundant needs, needs not in the field of the specialization and needs that will have no product based solutions. The second level of filtration was based on the criticality and frequency of occurrence of each need based on two factors- the clinician's multiple years of experience in the field and the observers' experience during the immersion period. Based on an unbiased numerical scoring system, each need was scored, and the needs were filtered based on these scores. The third level of filtering was based upon a literature review, and a feedback from clinicians from other hospitals, to identify the needs with significant data to back the clinical validation conducted at the hospitals by the observers. In this field validation exercise, the following questions were posed to 9 nephrologists from 8 different hospitals across Bangalore and Tumkur district.

1. How many patients do you see with Stage 4/5 CKD (say, per month) without fistulas or long term dialysis access sites?

2. How many cases of failed AV Fistulas do you see in your clinic?

3. How frequently do you see failed kidney biopsies due to insufficient sampling? How many cases lead to medical complications in kidney biopsies?

4. What in your opinion is the most important reason why PD is not adopted as a preferred means for dialysis in India?

5. What, in your opinion, is a more pressing issue - High costs associated with dialysis or Lack of access to quality dialysis centres in India?
This phase of validation filtering helped identify a top set of needs, which were relatively equal in terms of an opportunity for innovation.

The final level of filtering was done by identifying predicate devices or existing devices that are addressing similar problems for each need, and understanding the technological, and financial feasibility of innovation for a particular need. This helped identify the need which is a strategic fit and the relevant competitors for a company or group of people which would potentially want to work in that space of clinical innovation.

During the immersion, the authors also collected some data on costs, frequencies and impacts of certain negative outcomes at the clinical setting.

\section{Results}

The team comprised of a designer, an engineer, a senior nephrologist, and a clinician experienced in the biodesign process. The team completed a clinical immersion of 4 weeks at a tertiary referral hospital, making 54 detailed observations with significant negative outcomes and an equal number of clinical needs. A screenshot of a sample of the observation docket that was made is shown in Table 1.

Phase one of the filtration process eliminated redundant needs, bringing it down to 52 needs. Phase two used the criticality and frequency rating of the nephrologist, and of the designer and the engineer, to bring down the number of needs to 26 . Using a literature review and clinical feedback from 7 nephrologists from 6 different hospitals, the third phase of filtration was conducted, to come to top 15 needs. 5 of these needs were eliminated by identifying potential buyer environments, and a competitive landscape which would be easy to penetrate, and ease adoption of a solution. The filtering process is depicted in Table 2.

All interviewed clinicians validated the top needs, by citing examples from their own clinical setting. The clinicians agreed that an early way to detect chronic kidney disease would most definitely benefit the patients. The doctors approximately saw 5-6 end stage renal disease patients who arrived at their clinics without long term dialysis sites. AV fistula access related problems were quite common in their setup. Many clinicians also felt that the high costs of dialysis were a more pressing issue when compared to the lack of access to quality dialysis, arguing that the high costs impeded quality access. Failed kidney biopsies due to insufficient sampling were not a common occurrence in most of the setups where the nephrologists were interviewed. Very rarely did they lead to life threatening complications such as bleeding and shock. All doctors were of the opinion that peritoneal dialysis was expensive and required a lot of maintenance. The result was 10 significant clinical needs in the nephrology space, as shown in Table 3.

The top need of "A way to detect early onset of chronic kidney disease in people from rural areas so as to start early treatment and increase chances of cure." emerged after many rounds of through filtering. Literature data supported this top need. Chronic kidney disease has a prevalence of $0.79 \%$ in India and an estimated number of 163 people per million populations get afflicted with this illness every year.

Cost of each dialysis sitting was approximately INR 1200. Cost of a new dialyzer was approximately INR 5000. An AVF surgery costs approximately INR 7000. The neck catheter costs INR 4500. The AV graft surgery costs INR 30000, and the AV graft (made with tapered carbon coated material) costs around INR 33000. Balloon angioplasty surgery (to correct stenosis of veins) costs INR 25000. In many cases, 
if the length of the stenosis is long, multiple stents may be required and hence this is not preferred. The cost of a stent starts at Rs. 50000 and can go up to Rs. 80000 depending on the material. The dialyzer reprocessing machine costs anywhere between INR 3-5 Lakhs. The cost of an electron microscopy kidney biopsy procedure is approximately INR 6000. A transjugular renal biopsy costs INR 31000. These costs are the costs charged to the patient in the clinical setting where the authors carried out the immersion.

Per day 150 patients undergo a typical 4 hour haemodialysis session at the clinical setting. 35 hemodialysis machines operate in which 8 machines are reserved for HIV positive patients. 60-90 AVF surgeries are done each month. According to one interviewed clinician, 30 out of total 90 diabetic Stage 4-5 CKD patients per month present at the clinic for the first time. Every week around 1-2 CKD patients show symptoms of dehydration. Approximately 12-16 cases in one month suffered from severe swelling in the arm due to an unsuccessful angioplasty procedure to dilate stenosed veins. There were at least 2 cases a week in which patients suffered from cardiac complications due to renal disease.

\section{Discussion}

This article describes how a multi-disciplinary team studied a field of medicine from the clinical point of view in a structured manner to highlight 10 validated areas of clinical innovation to fit the Indian healthcare system. This improvised bio-design process can be used in

Table 1. Ten most significant clinical needs identified in Nephrology.

A way to detect early onset of chronic kidney disease in people from rural areas so as to start early treatment and increase chances of cure.

2 A more accurate way to assess the retained fluid volume in non-ambulatory

2 chronic kidney disease patients in order to carry out effective dialysis.

3 A safer way to perform haemodialysis in patients with deranged bleeding 3 parameters in order to prevent uncontrolled bleeding and shock.

4 A safer and effective way to reprocess the dialyzer after it has been used so as to prevent infections and spread of blood-transmitted diseases.

5 A better way to evaluate the patency of veins before insertion of IJV/ subclavian lines to prevent unnecessary costs and associated morbidities.

An effective way to monitor serum creatinine levels in chronic kidney disease

6 patients who have been discharged after haemodialysis in order to identify worsening of kidney function early and prevent delay in management.

An accurate way to monitor potassium levels in patients with chronic kidney

7 disease who have asymptomatic hyperkalemia in order to prevent cardiac complications.

8 A safer way to perform first time haemodialysis in patients with end stage renal disease in order to reduce the risk of hypotensive shock/ AV fistula collapse.

An effective way to maintain the patency of AV fistula for dialysis in chronic

9 kidney disease patients in order to prevent thrombosis, stenosis and corrective surgeries for AV fistula.

A safer way to perform haemodialysis in end stage renal disease patients without a

$10 \mathrm{ready} /$ mature AVF in order to prevent multiple temporary accesses in the neck and femoral veins and resulting infections and vein thrombosis until the AVF matures.

Table 2. Common procedural costs.

\begin{tabular}{|c|c|c|c|c|}
\hline Procedure & $\begin{array}{c}\text { OPD Costs } \\
\text { (INR) }\end{array}$ & $\begin{array}{c}\text { General Ward } \\
\text { Costs (INR) }\end{array}$ & $\begin{array}{c}\text { Private Ward } \\
\text { Costs (INR) }\end{array}$ & $\begin{array}{c}\text { AC Ward Costs } \\
\text { (INR) }\end{array}$ \\
\hline $\begin{array}{c}\text { Kidney Biopsy with } \\
\text { Disposal Gun }\end{array}$ & 900 & 1260 & 1620 & 2340 \\
\hline $\begin{array}{c}\text { Kidney Biopsy with } \\
\text { Reusable Gun }\end{array}$ & 800 & 1120 & 1440 & 2080 \\
\hline Catheter Removal & 70 & 100 & 130 & 2080 \\
\hline Femoral Access & 300 & 420 & 540 & 780 \\
\hline $\begin{array}{c}\text { Subclavian Access/ } \\
\text { Jugular Access }\end{array}$ & 300 & 420 & 540 & 780 \\
\hline $\begin{array}{c}\text { Wrist AVF } \\
\text { Catheterization }\end{array}$ & 240 & 340 & 430 & 620 \\
\hline
\end{tabular}

Table 3. Observation Docket of an Unsuccessful Angioplasty.

\begin{tabular}{|c|c|c|}
\hline $\begin{array}{c}\text { Place: } \\
\text { Nephrology Common Ward, } \\
\text { St. John's Medical College } \\
\text { and Hospital, Bangalore }\end{array}$ & $\begin{array}{c}\text { Title: } \\
\text { Unsuccessful Angioplasty }\end{array}$ & $\begin{array}{c}\text { Date: } \\
\text { 23 } 3^{\text {rd }} \text { March } 2015 \\
\text { 10:30 a.m. }\end{array}$ \\
\hline $\begin{array}{l}\text { Observation: A } 36 \text { year old } \\
\text { male had excessive swelling } \\
\text { in his left upper limb. The } \\
\text { reason for the swelling was } \\
\text { found to be a clotted supply } \\
\text { vein. A venous angioplasty } \\
\text { was advised by the doctor. } \\
\text { Due to financial constraints, } \\
\text { the patient refused a stent, } \\
\text { and chose to go for balloon } \\
\text { angioplasty. The procedure } \\
\text { reduced the swelling to } \\
\text { about } 25 \% \text { of the initial } \\
\text { state }(90 \% \text { blockage). The } \\
\text { swelling started recurring. } \\
\text { The patient was advised } \\
\text { once again to get an } \\
\text { angioplasty, but he refused } \\
\text { citing financial constraints. }\end{array}$ & $\begin{array}{l}\text { Patient Pathway: } \\
\text { The patient had a blocked } \\
\text { IJV and an infected } \\
\text { neckline. This was a result } \\
\text { of catheterization of the } \\
\text { IJV veins for dialysis. As } \\
\text { a result, the patient was } \\
\text { catheterized on his supply } \\
\text { vein (subclavicle vein) in } \\
\text { order to obtain access for } \\
\text { dialysis. The supply vein } \\
\text { also got blocked. This lead } \\
\text { to fluid buildup in his left } \\
\text { hand and hence the swelling. } \\
\text { The patient underwent a } \\
\text { balloon angioplasty, which } \\
\text { reduced the swelling by } 25 \% \\
\text { of the initial state. }\end{array}$ & $\begin{array}{l}\text { Insights: } \\
\text { Balloon Angioplasty surgery } \\
\text { costs Rs. 25,000. In many } \\
\text { cases, if the length of the } \\
\text { stenosis is too long, multiple } \\
\text { stents may be required, } \\
\text { which is not preferred. The } \\
\text { cost of a stent starts at Rs. } \\
50,000 \text { and can go up to Rs. } \\
80,000 \text { depending on the } \\
\text { material used. }\end{array}$ \\
\hline $\begin{array}{l}\text { Negative Outcome: } \\
\text { Severe swelling in the left } \\
\text { arm, ineffective balloon } \\
\text { angioplasty, patient distress, } \\
\text { discomfort. }\end{array}$ & $\begin{array}{l}\text { Prevalence: } \\
10-15 \% \text { of all balloon } \\
\text { angioplasty procedures } \\
\text { performed to dilate stenosis } \\
\text { fail. This amounts to } 50,000 \\
-75,000 \text { patients a year. } \\
(2012) \\
\text {-http://tinyurl.com/ku3otpb }\end{array}$ & $\begin{array}{l}\text { Need: } \\
\text { An affordable and effective } \\
\text { way to treat stenosed } \\
\text { veins in ward patients so } \\
\text { as to prevent associated } \\
\text { morbidities. }\end{array}$ \\
\hline $\begin{array}{l}\text { Frequency of Problem: } \\
12-16 \text { cases/month }\end{array}$ & $\begin{array}{l}\text { Frequency Source: } \\
\text { Dr. Sajeesh, Senior Resident, } \\
\text { Common Ward, SJMCH }\end{array}$ & $\begin{array}{l}\text { Existing Solutions: } \\
\text { Bypass Surgery, Stent, } \\
\text { Balloon Angioplasty }\end{array}$ \\
\hline
\end{tabular}

other fields of medicine to identify unmet clinical needs, as has been done before in the field of emergency medicine by a multidisciplinary group under the guidance of the same clinical expert in the bio-design process [6]. If successful, the process can aid in the development of indigenous products well suited for patients and clinicians in India. There are multiple benefits of using this process to identify unmet clinical needs, as have been highlighted in the following points.

\section{The involvement of a senior clinician}

Identifying unmet needs in a highly-specialized space such as nephrology requires an extensive understanding of the epidemiology of various disease states and the various methods existing for diagnosis and treatment. Thus, in such processes, the clinician's involvement is very important for the team to use their time efficiently and identify critical needs. The constant involvement of the senior nephrologist greatly influenced the team in finding valuable and extensive information to identify and validate clinical needs.

\section{The involvement of a designer and an engineer}

The process of a clinical immersion under the guidance of a senior nephrologist was highly beneficial for the designer and the engineer involved, in terms of understanding the field of nephrology in the Indian context. The two-month rigorous and intensive process of spending hours in the hospital, interacting with patients, nurses and doctors, and understanding the methods of diagnosis and treatment, helped the non-clinicians significantly enhance their understanding of nephrology, thus helping them extract meaningful information from the immersion to identify unmet needs (Figure 1).

\section{The structured and scientific filtering process}

Having a multi-disciplinary team helps in getting multiple points of view, and in discussing the observations extensively before making 


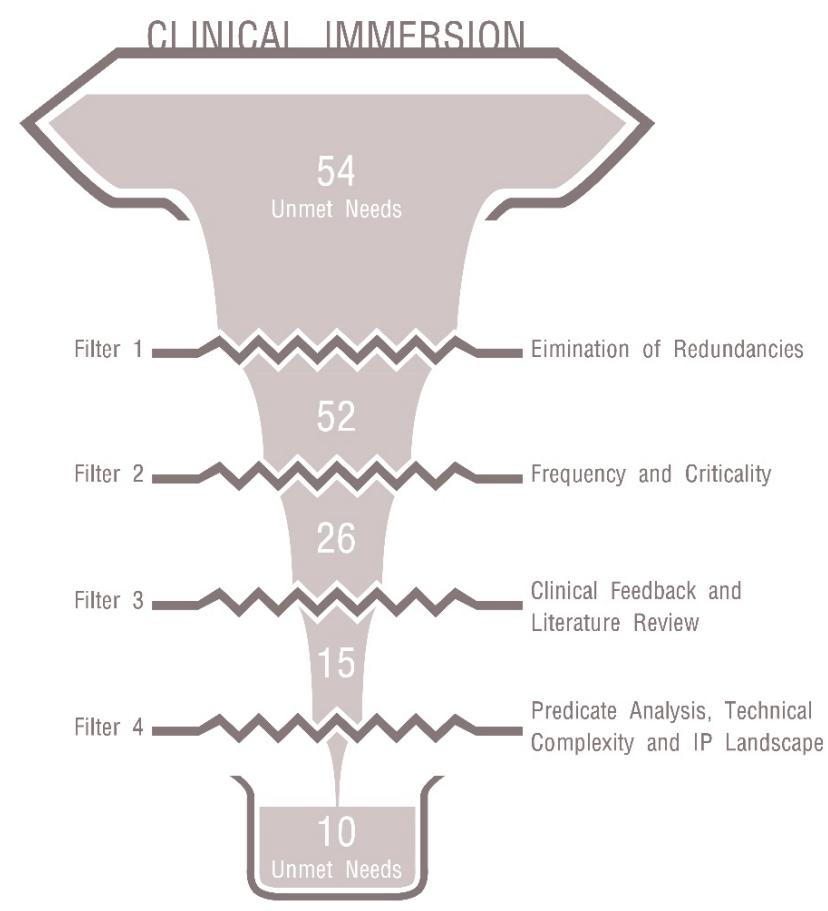

Figure 1. Depiction of the Filtering Process.

a judgement on its criticality. It is important to respect the clinicians' experience and their judgement in estimating clinical viability and feasibility of the occurrence of events, but it is equally important to respect an engineer's or a designer's understanding and experience in the time spent interacting with clinicians and patients. There is some amount of subjectivity that comes into the needs filtering process which one should be aware of and try to avoid. Certain elements of the filtering process, while necessary to narrow down to needs of utmost importance, can be difficult to ascertain, and must be justified and agreed upon by all members of the team. Since the process deals with identifying needs of the clinicians and the patients, it is difficult to objectively take decisions on the importance and relevance of certain observations made. The points of view vary between clinicians and non-clinicians due to a difference in experience and exposure. The expertise of all the team members plays a crucial role in the innovation process in a multi-disciplinary innovative set up, and hence must be understood and utilized in a mutually beneficial way. The absence of clinicians or non-clinicians in the team can lead to biased decisions or a narrowed view point towards certain subjects, and compromise on the importance given to the identified needs.

\section{The need for clinical validation from other healthcare centres}

The identification of needs over a period of two months at a superspeciality hospital was very effective and produced some pressing needs for the development of innovative solutions. But in order to study if the process followed indeed helped identify needs that the clinical experts in the field would agree with, it was important to validate the same at other hospitals. The clinical validation session conducted in Bangalore and Tumkur re-enforced the needs identified earlier, and provided wider points of view of these needs and potential ways of tackling the issues. It was also important to understand treatment in other hospitals as the facilities vary from hospital to hospital, depending upon the type of funding provided, the local patient intake, and other critical factors.
8 out of 9 nephrologists from the clinical feedback sessions felt that high cost was a major deterrent to the usage of Peritoneal Dialysis. This information was critical to understanding alternative ways of purifying blood for End Stage Renal Disease patients, and was not obtained from the clinical immersion held at St. John's Hospital, as Peritoneal Dialysis is not performed there.

St. John's hospital has one of the largest dialysis centres in India, with 40 dialysis units and over 150 dialysis sittings happening everyday. On the contrary, the Tumkur General Hospital has a 6 bedded dialysis unit, and around 15 sittings happening in a day. The two hospitals have very different requirements in terms of improvement of the infrastructure and clinical needs of the patients. CKD Patients in St. John's hospital need efficient sterilization techniques for reprocessing the dialyzer as a significant population of the dialysis patients suffer from HIV AIDS, and a poorly reprocessed dialyzer may pass on the disease to a healthy patient. On the other hand, Tumkur General Hospital does not cater to HIV patients, and focusses more towards improvement of the nursing staff to take better care of existing patients in the dialysis unit.

The above two examples have been used to exemplify the need for an extended study of nephrology from other doctors and hospitals to get a wholesome, unbiased outcome in terms of needs identification and validation.

\section{Interacting with patients and clinicians}

From a non-clinician's perspective, it is important to understand that innovation cannot take place without empathizing with the stakeholders in question. Conducting a clinical immersion in a hospital must involve the highest of regards for the patients' and clinicians' time and availability. One cannot disregard the fact that these patients are currently under some form of biological, social or occupational distress, and must be empathised with and not troubled by unnecessary prodding and probing. In India, the ratio of clinicians to patients is highly disproportionate, resulting in over-worked clinicians with barely enough time to tend to patients. In addition, a number of permission and trust issues surface in a clinical set-up where non-clinicians interact with patients. This is addressed in the Biodesign process which emphasizes on appropriate training on communication skills and interpersonal skills. One must appreciate the effort of a clinician working towards bio-medical innovation, apart from continuing his or her daily practice, and complement the clinician's clinical practice, rather than disturb it.

The clinicians, clinical staff and the patients had been ensured that the data collected was going to be used for the benefit of future patients, and that it will not be misused, and hence they felt obliged to provide whatever knowledge they had for the questions asked. Some of them were even interested to know how an engineer and designer were collecting data to identify potential products for the improvement of medical healthcare. Although there were clinicians who felt it was a waste of their time to answer the team's questions, most of the staff and patients were very cooperative.

\section{The importance of a thorough needs identification and validation process}

When attempting to design solutions for clinical needs, it is important to know that these solutions can change the biological, social and/or occupational conditions of a large number of patients. Also, the development of a product for use in a clinical setting requires many years of testing and a proportional amount of financial investment before it can be launched in the market. Hence it was important for 
us to thoroughly investigate the needs, understand the problems, and then concentrate on developing solutions. The two-month long immersion and the multiple rounds of filtering ensured that the most pressing matters came on top with enough information and validation to support any development of innovative products.

\section{Conclusion}

The modified structured process for unmet clinical needs identification takes into consideration the context of Indian Healthcare Systems and helps create a validated database of clinical needs for future innovation and invention of medical devices and diagnostics for the Indian Market. The process had to be altered significantly and structured to obtain an output of ten compelling medical needs in the field of nephrology.

The process allowed for identification of unmet clinical needs in the focus area of Nephrology. The negative outcomes were well understood through four rounds of rigorous filtering that successively eliminated redundant and low-impact needs. The filtering parameters also ensured better insights into the disease space, predicate device analysis using a technical feasibility and buyer capacity study, and literature data on incidence and prevalence of the negative outcomes.

A scientific and data driven approach allowed objective evaluation of the needs leading to the top need most compelling needs in the Nephrology space. Currently the team is continuing its work towards identifying a need and create affordable and innovative tools to make healthcare more accessible and suited for the Indian market.

This methodology can be used effectively across healthcare settings, specialities andgeographies to identify critical areas that need innovative solutions in the Indian market.

\section{Acknowledgements}

The authors are grateful to St. John's Medical College and Hospital for providing access for Clinical observership. The authors acknowledge
Stanford Biodesign for the process on unmet need analysis. The authors also acknowledge InnAccel Acceleration Services for providing the observers with the opportunity to conduct the clinical immersion and guide the observers through the process to come out with significant contributions to the MedTech Innovation space in India.

Contributors: The study was proposed by JC, and executed by SS and PAK under the clinical guidance of RPD. JC co-wrote the manuscript. All authors have read and approved the final manuscript.

Funding: This study is funded by InnAccel acceleration services private limited (IA), which has financial interests in the medical technology industry.

\section{References}

1. Jha V (2013) Current status of end-stage renal disease care in India and Pakistan. Kidney International Supplements 3:157-160.

2. Mani MK (2005) Experience with a program for prevention of chronic renal failure in India. Kidney IntSuppl: S 75-78. [Crossref]

3. Anchala R, Kannuri NK, Pant H, Khan H, Franco OH, et al. (2014) Hypertension in India: a systematic review and meta-analysis of prevalence, awareness, and control of hypertension. J Hypertens 32: 1170-1177. [Crossref]

4. Kaveeshwar SA, Cornwall J (2014) The current state of diabetes mellitus in India Australas Med J 7: 45-48. [Crossref]

5. Pradeep Arora, VecihiBatuman (2016) Chronic Kidney Disease: Practice Essentials, Background, Pathophysiology.

6. Khanna U (2009) The economics of dialysis in India. Indian J Nephrol 19: 1-4 [Crossref]

7. Pacific Bridge Medical (2013) India's Dialysis Market.

8. Veerappan I, Abraham G (2013) Chronic Kidney Disease: Current Status, Challenges and Management in India.

9. Chaturvedi J, Logan A, Narayan G, Kuttappa S (2015) A structured process for unmet clinical need analysis for medical device innovation in India: early experiences. $B M J$ Innovations.

10. Zenios S, Makower J, Yock P (2010) Biodesign Cambridge: Cambridge University Press.

Copyright: (C2017 Kumar PA. This is an open-access article distributed under the terms of the Creative Commons Attribution License, which permits unrestricted use, distribution, and reproduction in any medium, provided the original author and source are credited. 